\title{
U50' Small Nucleolar RNA
}

National Cancer Institute

\section{Source}

National Cancer Institute. U50' Small Nucleolar RNA. NCI Thesaurus. Code C131748.

U50' small nucleolar RNA (75 bases) is encoded by the human SNORD50B gene. This oligoribonucleotide plays a role in ribosomal RNA methylation. 